\title{
HOME OFFICE E MOBILIDADE URBANA NO PERÍODO DA PANDEMIA: UMA PESQUISA DE OPINIÃO NA CIDADE DE SÃO PAULO
}

\author{
Alyce Oliveira Silva \\ FATEC-ZONA LESTE - CEETEPS, alyce.silva@fatec.sp.gov.br \\ Camila Aparecida Gomes Moura \\ FATEC-ZONA LESTE - CEETEPS, camila.moura@fatec.sp.gov.br \\ Camila Pereira Braga \\ FATEC-ZONA LESTE - CEETEPS, camila.pereirabraga@gmail.com \\ Eliacy Cavalcante Lélis \\ FATEC-ZONA LESTE - CEETEPS, eliacy.lelis@fatec.sp.gov.br \\ Wagner Alves Da Silva \\ FATEC-ZONA LESTE - CEETEPS, wagner.kxa@gmail.com
}

\section{RESUMO}

A pandemia causada pela COVID-19 implicou em modificações no cotidiano das pessoas, e principalmente, considerando o isolamento social como principal estratégia adotada - no mercado de trabalho. O "Home Office" foi estratégia em cerca de $46 \%$ das empresas brasileiras e isso, consecutivamente, gerou impacto direto na mobilidade urbana da cidade, em especial ao transporte público urbano, utilizado como principal meio de transporte dos profissionais. O objetivo deste artigo é apresentar a opinião de profissionais que aderiram o Home Office durante o período de pandemia e isolamento social, e se acreditam que a estratégia pode ser benéfica ao sistema de transporte público da cidade de São Paulo. A pesquisa é composta por teorias bibliográficas e suporte de uma pesquisa de opinião com amostra de 91 participantes. Apresenta-se nesse documento uma reflexão para a possibilidade de setores manterem essa prática após o fim do isolamento social, reduzindo a utilização do transporte pelos profissionais e impactando positivamente na mobilidade urbana da cidade.

Palavras-Chave: Pandemia. Mobilidade Urbana. Transporte Público. Home Office.

\begin{abstract}
The pandemic caused by COVID-19 implied changes in people's daily lives, and especially - considering social isolation as the main strategy adopted - in the labor market. The "Home Office" was a strategy in about $46 \%$ of Brazilian companies and this, consecutively, generated a direct impact on the urban mobility of the city, especially urban public transport, used as the main means of transport for professionals. The aim of this article is to present the opinion of professionals who joined the Home Office during the period of pandemic and social isolation, and if they believe that the strategy can be beneficial to the public transportation system of the city of São Paulo. The research is composed of bibliographic theories and support of an opinion survey with a sample of 91 participants. This document presents a reflection for the possibility of sectors maintaining this practice after the end of social isolation, reducing the use of transportation by professionals and positively impacting on the urban mobility of the city.
\end{abstract}

Key-words: Pandemic. Urban Mobility. Public Transport. Home Office. 


\section{INTRODUÇÃO}

É fato que atualmente vive-se momentos únicos e difíceis, graças a pandemia do novo coronavírus (Covid-19). Começou paralisando a China, e rapidamente atingiu diversos países, inclusive o Brasil.

A pandemia da Covid-19 surpreendeu a todos, por conta da alta capacidade de transmissão do coronavírus, o mundo viu-se obrigado a buscar se adaptar rapidamente e de muitas maneiras, sendo o isolamento social como um dos meios mais eficazes indicado pelas autoridades ligadas à saúde (BRIDI et al, 2020).

Com a pandemia e a restrição de circulação, houve um aumento da adoção de empresas brasileiras ao home office (Trabalho em casa), onde teve um grande potencial de repercussão na mobilidade urbana. Impacta diretamente a promoção da mobilidade urbana sustentável ao reduzir congestionamentos e tornar mais eficiente o uso do tempo e da energia, e consequentemente a questão ambiental, por conta da menor quantidade de gases liberados.

A principal justificativa para o tema proposto está associada ao momento que estamos vivendo, onde o home office se tornou a principal alternativa para as empresas nesta época de pandemia, levando em conta o risco de contaminação dentro dos transportes públicos. Trabalhar de casa pode contribuir efetivamente para a diminuição dos engarrafamentos e aliviar a superlotação do transporte público urbano.

O objetivo geral do artigo é apresentar a opinião dos profissionais que aderiram o Home Office durante a pandemia, e se acreditam que a estratégia pode ser benéfica ao sistema de transporte público da cidade de São Paulo.

O objetivo específico é estabelecer a relação entre o home office e a mobilidade urbana.

\section{EMBASAMENTO TEÓRICO}

\subsection{Política Nacional de Mobilidade Urbana}

Segundo Brasil (2012, s.p.), a lei de mobilidade urbana aponta que na definição da PNMU Política Nacional de Mobilidade Urbana, o termo Mobilidade Urbana refere-se à "condição em que se realizam os deslocamentos de pessoas e cargas no espaço urbano".

No passado o conceito de Mobilidade Urbana se restringia apenas a circulação de veículos, atualmente, esse conceito ganhou uma abrangência maior, fazendo vínculo direto com a organização territorial e a sustentabilidade das cidades (TRIBUNAL DE CONTAS DA UNIÃO, 2010). 
Datado de janeiro de 2012 , a Lei $n^{\circ} 12.587 / 12$ foi apresentada de modo a estabelecer uma Política Nacional de Mobilidade Urbana (PNMU), que tem como princípio ser um documento base, de orientação governamental, abordando o papel da União, Estados e Municípios, no que se refere a implantação da política, para o desenvolvimento da mobilidade urbana, visando a sustentabilidade como princípio fundamental. O documento também estabelece os direitos dos usuários quanto a esfera de mobilidade, direciona a regulação dos serviços de transporte público e coletivo e traz as diretrizes que alicerçam o planejamento e a gestão dos sistemas de mobilidade urbana (SECRETARIA NACIONAL DE MOBILIDADE URBANA, 2018).

O Sistema Nacional de Mobilidade Urbana, traz os recursos, que permite garantir o deslocamento de cargas e pessoas dentro do Municipal.

A Política Nacional de Mobilidade Urbana (2012), estabelece que municípios que tenham mais de 20 mil habitantes, criem seus próprios planos de mobilidade urbana, assim os municípios centralizam os seus projetos e formulam propostas para o desenvolvimento local.

\subsection{Panorama do Transporte Público Coletivo no Município de São Paulo}

De acordo com a Política Nacional de Mobilidade Urbana (2012), transporte público coletivo é definido como um "serviço público de transporte de passageiros acessível a toda a população mediante pagamento individualizado, com itinerários e preços fixados pelo poder público", de acordo com os princípios estabelecidos pela mesma política, o transporte público coletivo deve ser priorizado quando comparado ao transporte individual motorizado.

No município Paulista, o transporte público coletivo por ônibus é o meio de transporte mais utilizado (MOBILIZE, 2018). Segundo dados da SPTrans (empresa responsável pelo sistema de transporte de ônibus na cidade de São Paulo), a média diária de pessoas transportadas por esse modal está em torno de 10 milhões de passageiros, demonstrando assim a dominância do modal na cidade. Segundo a empresa, a frota dos coletivos cadastrados está em torno de 14.500 ônibus, que estão distribuídos em 1.300 linhas, a distância percorrida em um dia útil é de 3 milhões de quilômetros rodados, isso representa um total de $43 \%$ de utilização do modal quando comparado a outros modais de transporte público coletivo (MOBILIZE, 2018).

De acordo com a pesquisa Viver em São Paulo realizada pela Rede Nossa São Paulo e Ibope Inteligência (2018), os serviços de metrô correspondem a 12\% das viagens realizadas pelos usuários, enquanto $3 \%$ das viagens realizadas são via trem.

\subsection{A pandemia COVID-19 e o isolamento social}


Não é segredo que todo o planeta tem vivido uma nova realidade com a pandemia do novo coronavírus. Foi no dia 31 de dezembro de 2019, que a Organização Mundial da Saúde (OMS) recebeu da Comissão Municipal da cidade de Wuhan na China, informações a respeito de casos de pneumonia viral, que até então tinha a sua causa desconhecida para a população médica (ORGANIZAÇÃO MUNDIAL DA SAÚDE, 2020).

Ao longo da história, houveram pandemias que marcaram a humanidade, como por exemplo, a Peste Negra e a Gripe Espanhola. Agora, passa-se por mais uma pandemia histórica, a da Covid -19 (Coronavírus).

O contágio acontece através de aperto de mãos contaminadas, saliva, objetos contaminados, tosse, espirros e outros. E os sintomas mais comuns são dor de garganta, tosse, febre, coriza, perda de olfato e paladar e em casos mais graves, falta de ar.

No Brasil, desde março de 2020 tem-se visto diversas mudanças no cotidiano da população, principalmente relacionado ao distanciamento e isolamento social.

Com o intuito de frear a onda de contaminação, foi decretada quarentena no país, permitindo o funcionamento apenas dos serviços essenciais, como farmácias, supermercados e postos de combustíveis.

Quadro 1. Classificação das fases durante a pandemia

\begin{tabular}{|c|c|c|c|c|c|}
\hline Kritério & Indicador & $\begin{array}{c}\text { Fase } \overline{1} \\
\text { Alerta máximo }\end{array}$ & $\begin{array}{l}\text { Fase } 2 \\
\text { Controle }\end{array}$ & $\begin{array}{c}\text { Fase } 3 \\
\text { Flexibilização }\end{array}$ & $\begin{array}{c}\text { Fase } 4 \\
\text { Abertura parcial }\end{array}$ \\
\hline \multirow{2}{*}{$\begin{array}{l}\text { Capacidade } \\
\text { do Sistema } \\
\text { de Saúde }\end{array}$} & $\begin{array}{l}\text { Taxa de ocupação de } \\
\text { leitos UTI COVID }\end{array}$ & $\begin{array}{l}\text { Acima de } \\
\quad 80 \%\end{array}$ & $\begin{array}{c}\text { Entre } 70 \% \mathrm{e} \\
80 \%\end{array}$ & $\begin{array}{c}\text { Entre } 70 \% \\
\text { de } 60 \%\end{array}$ & $\begin{array}{l}\text { Albaixo de } \\
60 \%\end{array}$ \\
\hline & $\begin{array}{l}\text { Leitos UTI COVID / 100k } \\
\text { habitantes }\end{array}$ & $\begin{array}{c}\text { Abaixo de } \\
3,0\end{array}$ & $\begin{array}{c}\text { Entre } 3,0 \text { e } \\
5,0\end{array}$ & $\begin{array}{c}\text { Acima de } \\
5,0\end{array}$ & $\begin{array}{c}\text { Acima de } \\
5,0\end{array}$ \\
\hline \multirow{3}{*}{$\begin{array}{c}\text { Evolução } \\
\text { da } \\
\text { epidemia }\end{array}$} & $\begin{array}{l}\text { \# de novos casos últimos } \\
7 \text { dias / \# de novos casos } \\
7 \text { dias anteriores }\end{array}$ & $\begin{array}{c}\text { Acima de } \\
2,0\end{array}$ & $\begin{array}{c}\text { Entre } 1,0 \mathrm{e} \\
2,0\end{array}$ & $\begin{array}{c}\text { Entre } 1,0 \mathrm{e} \\
2,0\end{array}$ & $\begin{array}{c}\text { Albaixo de } \\
1,0\end{array}$ \\
\hline & $\begin{array}{l}\text { \# de novas internações } \\
\text { últimos } 7 \text { dias / \# de } \\
\text { novas internações } 7 \text { dias } \\
\text { anteriores }\end{array}$ & $\begin{array}{c}\text { Acima de } \\
1,5\end{array}$ & $\begin{array}{c}\text { Entre } 1,0 \mathrm{e} \\
1,5\end{array}$ & $\begin{array}{c}\text { Entre } 0,5 \mathrm{e} \\
1,0\end{array}$ & $\begin{array}{c}\text { Alsaixo de } \\
0,5\end{array}$ \\
\hline & $\begin{array}{l}\text { \# de óbitos por COVID } \\
\text { nos últimos } 7 \text { dias / \# de } \\
\text { óbitos por COVID nos } 7 \\
\text { dias anteriores }\end{array}$ & $\begin{array}{c}\text { Acima de } \\
2,0\end{array}$ & $\begin{array}{c}\text { Entre } 1,0 \mathrm{e} \\
2,0\end{array}$ & $\begin{array}{c}\text { Entre } 0,5 \mathrm{e} \\
1,0\end{array}$ & $\begin{array}{c}\text { Albaixo de } \\
0,5\end{array}$ \\
\hline
\end{tabular}

Fonte: Governo de São Paulo (2020)

De acordo com Tajra (2020), a Secretaria de Estado da Saúde estipulou cores para definir as etapas de flexibilização, sendo elas: Vermelho, significando alerta máximo, com liberação de apenas os serviços essenciais; Laranja, fase de atenção, início da flexibilização de setores com baixo risco para a saúde; Amarelo, começando a abertura controlada de mais atividades; Verde, abertura 
parcial de outros ramos, mas ainda com restrições; Azul, normal controlado: todas as atividades têm permissão para funcionar, mas com medidas de distanciamento e higiene sempre, com uso de máscaras e álcool gel.

Figura 1. Panorama atual do Estado de São Paulo - visão por Departamento Regional de Saúde (DRS)

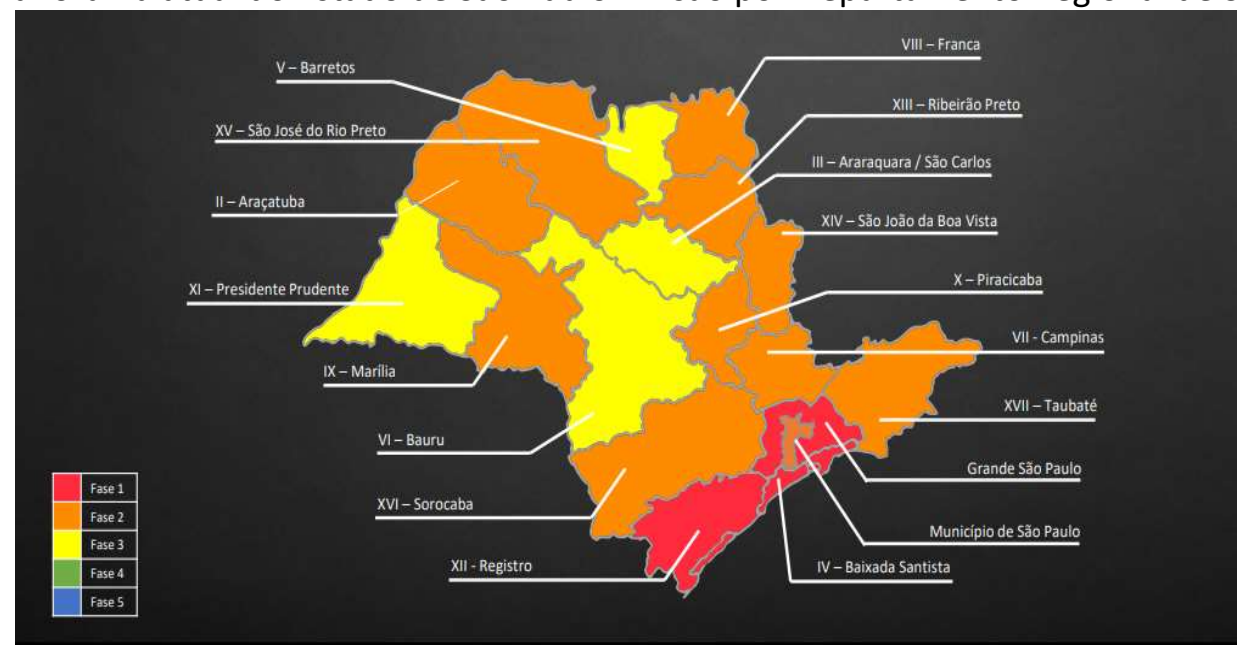

Fonte: Governo de São Paulo (2020)

Para a prevenção da doença recomenda-se, higienização das mãos, não compartilhar objetos pessoais, manter os ambientes bem ventilados, evitar aglomerações, contato físico, uso de álcool gel e de máscara cirúrgica ou de tecido, sempre que for necessário sair de casa.

O confinamento imposto pela Covid-19, que já foi descrito como o "maior experimento psicológico do mundo", vem colocando à prova a capacidade humana de extrair sentido do sofrimento e desafiando os indivíduos e a sociedade (VAN HOOF, 2020 apud LIMA, 2020).

\subsection{Home office ocasionado pela pandemia do novo coronavírus (Covid-19)}

O ano de 2020 se iniciou com uma crise que vai entrar para a história, a pandemia do novo coronavírus covid-19. Frente a este contexto, várias medidas foram impostas, sendo uma das principais, o isolamento social.

Tendo o isolamento social como a principal estratégia de prevenção, logo causou um grande impactou na vida humana, principalmente tratando-se do mercado de trabalho, já que várias empresas se viram obrigadas a adotar o Home Office.

Pode-se definir "Home Office" como trabalho a distância realizado em casa, e segundo um estudo elaborado pela Fundação Instituto de Administração (FIA), ele foi utilizado como estratégia por cerca de $46 \%$ das empresas brasileiras (MELLO, 2020). 
Algumas empresas já praticavam o home office, porém passou a ser urgência para a grande maioria, ou seja, o que antes era uma exceção acabou virando uma regra (LOSEKANN; MOURÃO, 2020 p. 72).

Vários foram os desafios enfrentados, tanto para as organizações, quanto para os funcionários. Problemas com espaço em casa, equipamentos adequados, velocidade de internet, segurança da informação, aprendizado de novas tecnologias e sem contar o desafio de conciliar a vida pessoal e a profissional no mesmo espaço.

Em contrapartida, se por um lado tiveram desafios, por outro vieram as oportunidades e os pontos positivos. Muitos trabalhadores começaram a render mais, por conta da otimização do tempo, o conforto do lar e a sensação de segurança contra o vírus, isto é, os cansaços físico e mental diminuíram consideravelmente, também levando em conta as horas economizadas decorrentes do não deslocamento casa-trabalho e vice-versa.

\section{METODOLOGIA DE PESQUISA}

Trata-se de uma pesquisa bibliográfica exploratória, pois o tema retrata uma realidade recente e carente de mais pesquisas. Esta é uma pesquisa descritiva, que discute os resultados com o método dialético, visando abrir a reflexão sobre a interface entre o home office e a mobilidade urbana.

Foi desenvolvido um questionário semiaberto, executado pela ferramenta Google Forms, composto por 12 questões, relacionadas ao home office e transporte público durante o período de pandemia. Obteve-se 91 respostas, com base na análise e integridade destas, e também da pesquisa bibliográfica, realizou-se a validação dos dados e a escrita do trabalho. 


\section{RESULTADOS E DISCUSSÃO}

A amostra da pesquisa consiste na resposta de 91 participantes, sobre um questionário composto por 12 perguntas, sendo estas divididas em 10 perguntas de múltipla escolha com respostas fechadas e objetivas, e 2 perguntas abertas, com resposta curta. Os dados coletados através do questionário serão apresentados em forma de gráfico, com respostas medidas em percentuais para possibilitar melhor visualização e entendimento do leitor.

Quanto ao perfil dos participantes, obteve-se os resultados, conforme apresentado nos Gráfico 1 e Gráfico 2.

Gráfico 1. Qual sua idade?

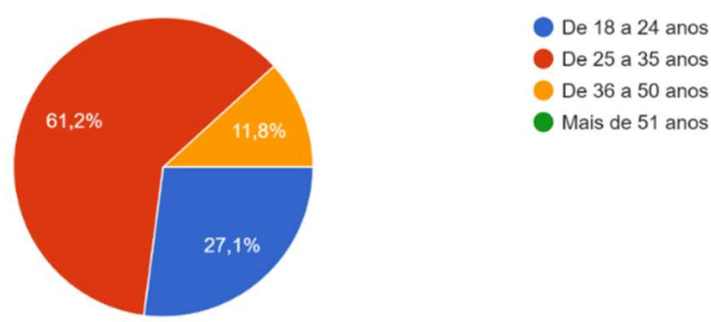

Fonte: Autores (2021)

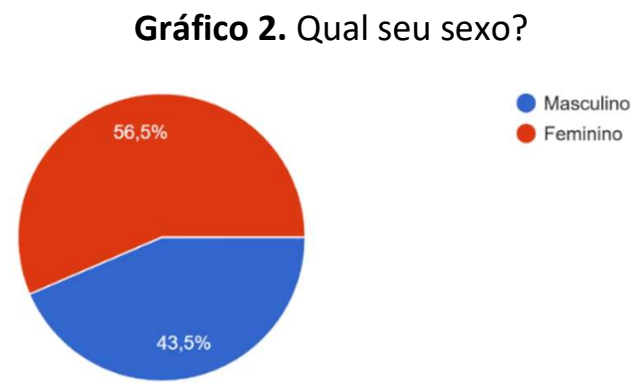

Fonte: Autores (2021)

Entre o total de 91 participantes 61,2\% estão entre 25 a 35 anos, 27,1\% entre os 18 a 24 anos e $11,8 \%$ entre os 36 a 50 anos. E, com base nas respostas, $56,5 \%$ dos participantes são do sexo feminino e $43,5 \%$ são do sexo masculino.

Em relação ao ramo de atividade dos participantes, obteve-se respostas, conforme Gráfico 3.

Gráfico 3. Qual ramo de atividade trabalha?

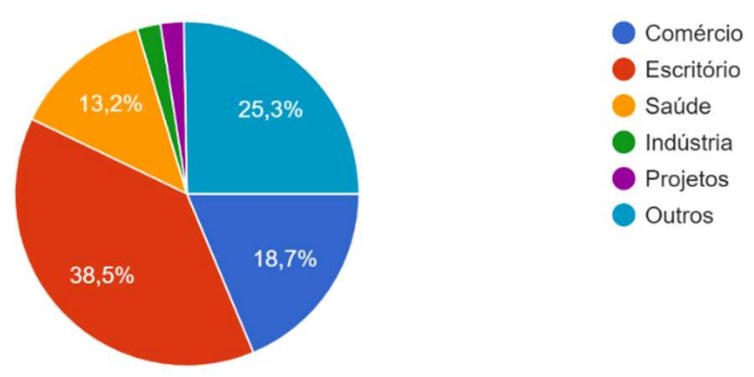

Fonte: Autores (2021)

A porcentagem de $38,5 \%$ dos participantes trabalham em escritório, 25,3\% responderam outros ramos de atividade, $18,7 \%$ realizam suas atividades no comércio, contra $2,2 \%$ em projetos e 2,2\% na indústria. 
Sobre o trabalho em Home Office ter seu início anteriormente ou somente durante a pandemia, os participantes responderam, conforme Gráfico 4.

Gráfico 4. Iniciou o Home Office durante a pandemia?
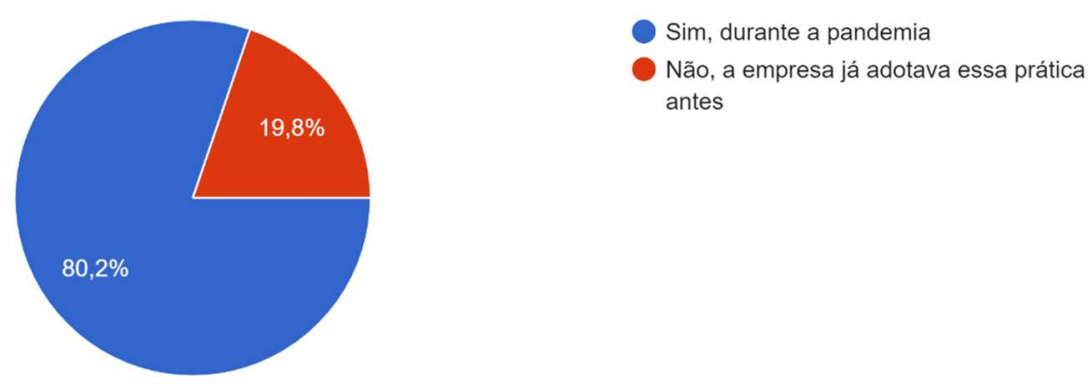

Fonte: Autores (2021)

Em resposta a essa questão, 80,2\% tiveram início do trabalho em Home Office somente no período de pandemia, contra $19,8 \%$ dos participantes que já adotavam essa pratica.

Sobre a jornada de trabalho em Home Office, obteve-se as resposta no Gráfico 5.

Gráfico 5. Quanto a jornada de trabalho em Home Office?

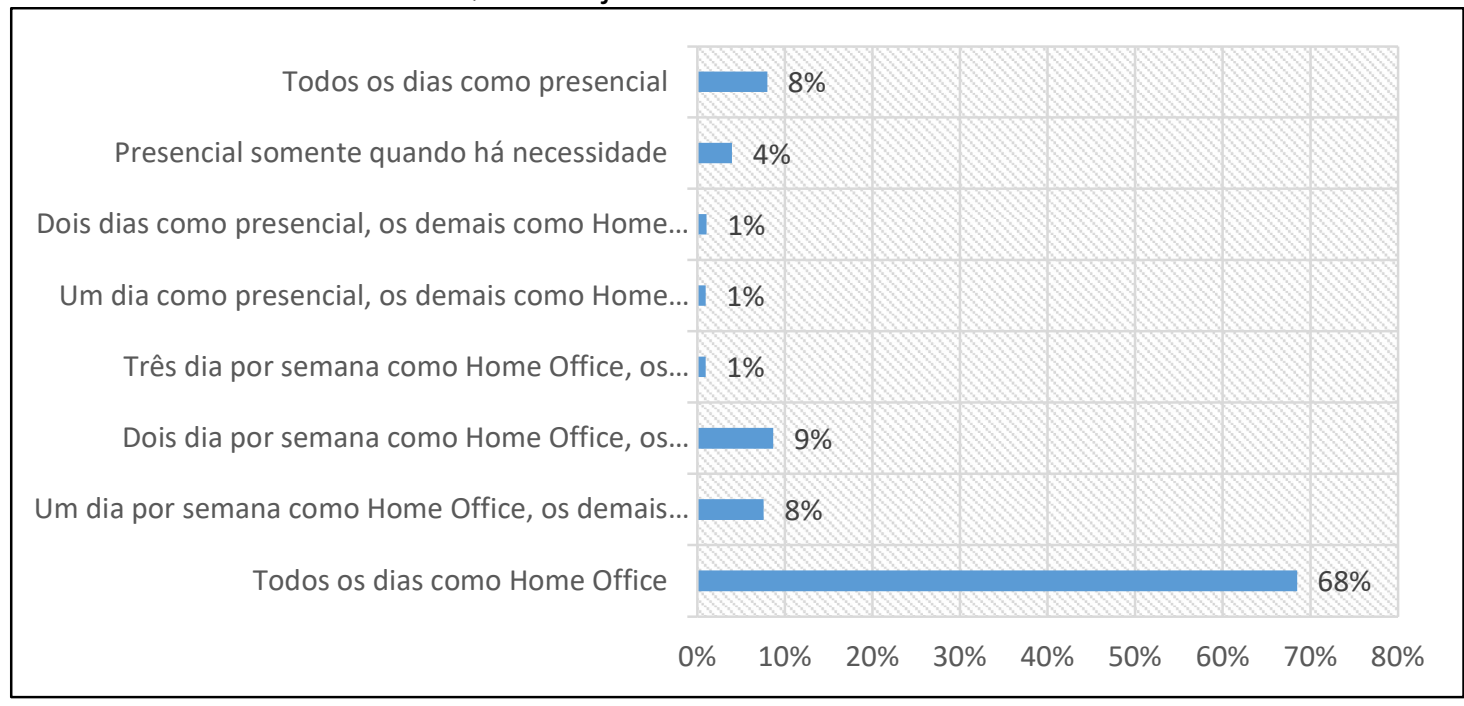

Fonte: Autores (2021)

Conforme apresentado, a opção de mais alta porcentagem é Todos os dias como Home Office, seguido por Dois dias por semana como Home Office, os demais presenciais (9\%), e ambas Todos os dias como presencial e Um dia por semana como Home Office, os demais presenciais com $8 \%$, Presencial quando há necessidade com $4 \%$ e o restante com $1 \%$ apenas.

Sobre as modalidades que seriam utilizadas, caso não estivessem trabalhando em Home Office, os participantes responderam, conforme apresentado no Gráfico 6. 
Gráfico 6. Caso estivesse trabalhando presencialmente quais modalidades de transporte usaria até o trabalho?

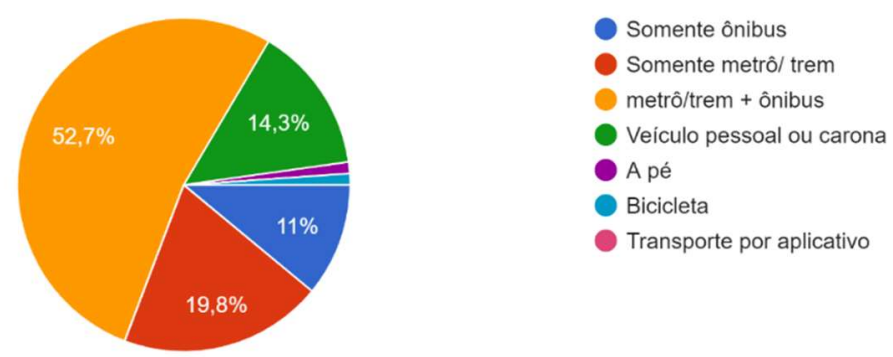

Fonte: Autores (2021)

Em resposta a essa pergunta, o total de $52,7 \%$ dos participantes utilizariam metrô ou trem com integração a ônibus, 19,8\% utilizariam somente metrô ou trem, 14,3\% veículo pessoal ou carona, $11 \%$ utilizariam ônibus até o trabalho, $1,1 \%$ a pé e $1,1 \%$ de bicicleta.

Sobre os principais problemas apresentados nas modalidades utilizadas pelos participantes, suas respostas seguem apresentadas no Gráfico 7.

Gráfico 7. A modalidade de transporte que você utilizaria enfrenta quais dificuldades ou problemas?

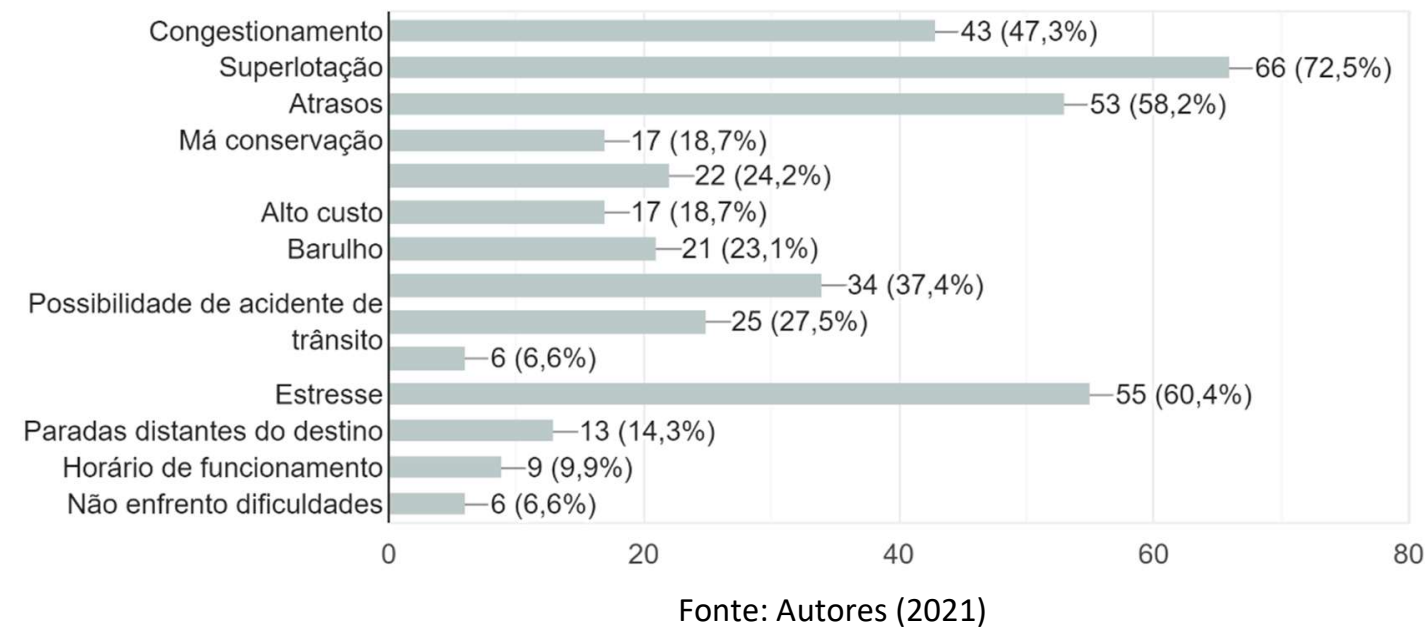

O problema com a mais alta porcentagem, representando $72,5 \%$ é a superlotação, em seguida, com $60,4 \%$ o estresse, $58,2 \%$ sofrem dificuldades com atrasos, $47,3 \%$ congestionamentos, $37,4 \%$ falta de segurança - alto risco de assédio, 27,5\% responderam dificuldades de acidente de trânsito, 24,2\% enfrentam dificuldades com alto risco de assalto, $18,7 \%$ acreditam que a má conservação será uma das dificuldades, assim como o alto custo com a mesma porcentagem, 14,3\% informa que a dificuldade seja as paradas distantes do destino, 9,9\% o horário de funcionamento e com porcentagens iguais de 6,6\% a baixa acessibilidade e o não enfrentam dificuldades na utilização de sua modalidade de uso ao serviço em atividade presencial.

Quanto a modalidade utilizada, em horário de pico, responderam conforme Gráfico 8. 
Gráfico 8. No horário de pico qual modalidade de transporte você utiliza?

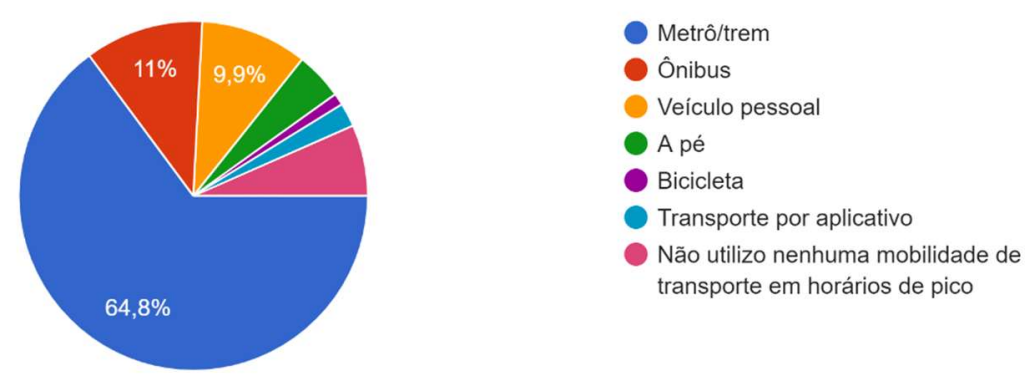

Fonte: Autores (2021)

As respostas dos participantes foi dada em $64,8 \%$ utilizam o metrô ou trem no horário de pico, $11 \%$ responderam que utilizam ônibus, 9,9\% veículo pessoal, 6,6\% não utilizam nenhuma modalidade de transporte em horários de pico, 4,4\% utilizam a modalidade a pé, 2,2\% utilizam transportes por aplicativo e somente $1,1 \%$ utilizam a bicicleta.

Sobre a quantidade de horas que os participantes levariam, caso estivessem trabalhando presencialmente, responderam conforme Gráfico 9.

Gráfico 9. Quantas horas levaria para chegar ao trabalho?

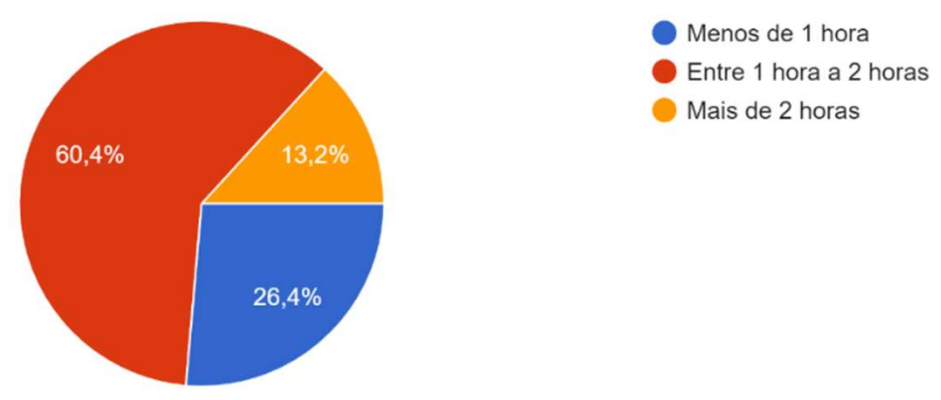

Fonte: Autores (2021)

A maior representação no gráfico de $60,4 \%$ levaria entre 1 hora a 2 horas para chegar ao trabalho em atividades presenciais, $26,4 \%$ menos de uma hora e 13,2\% levariam mais de 2 horas até seu destino ao trabalho.

Questiona-se os participantes sobre como tem aproveitado o tempo livre antes destinado a sua movimentação até o trabalho e as respostas revelaram que estão destinando o tempo para dormir mais (36\%), lazer - ouvir música, assistir filmes ou séries, jogar videogame, leitura (27\%) e se dedicar aos estudos (22\%), conforme o Quadro 10 apresenta. 
Gráfico 10. Como tem aproveitado o tempo livre antes destinado ao trajeto até o trabalho?

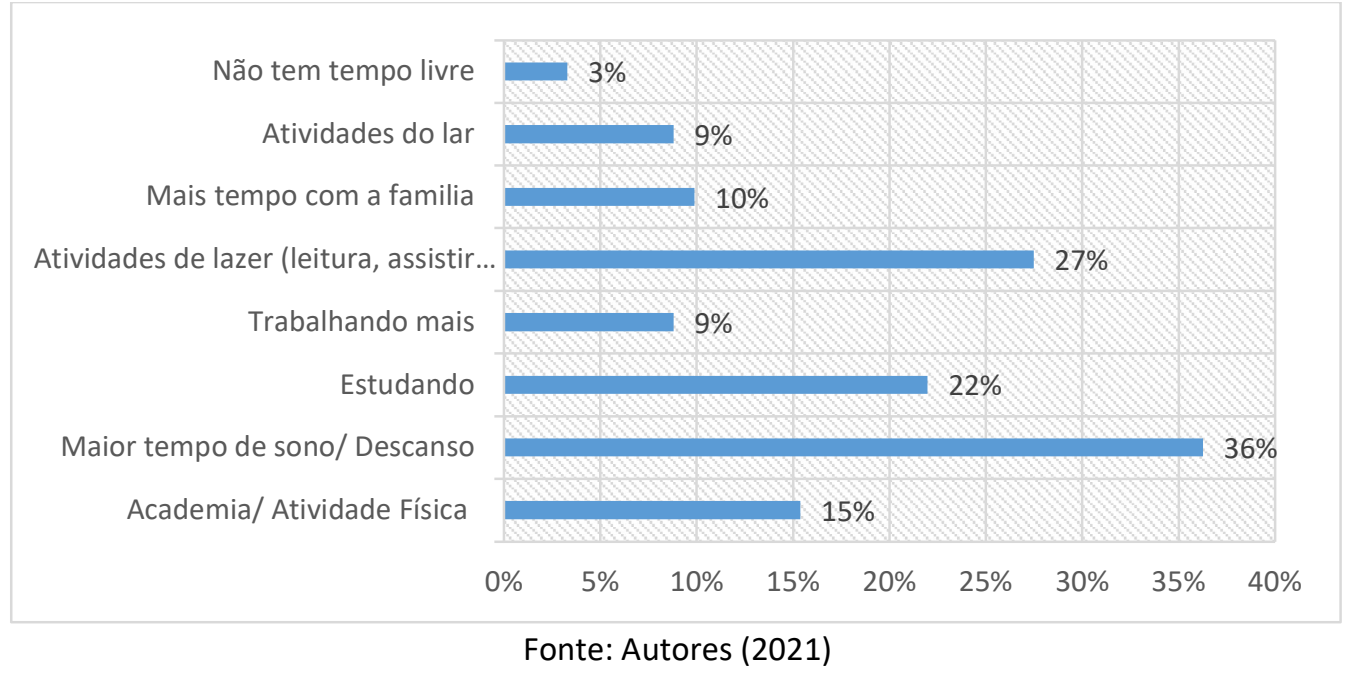

Pergunta-se a opinião dos participantes sobre o incentivo do Poder Público para o trabalho Home Office, ser uma boa estratégia para minimizar os problemas de mobilidade urbana, responderam conforme representa o Gráfico 11.

Gráfico 11. Acredita que um incentivo ao Home Office por parte do Poder Público poderia vir a ser uma estratégia para minimizar os problemas de mobilidade urbana do transporte público?

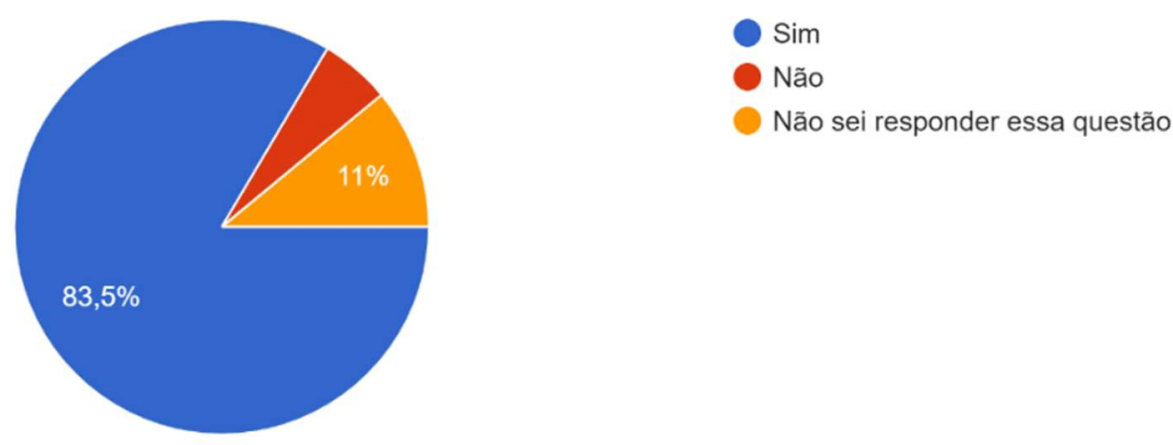

Fonte: Autores (2021)

O percentual de $83,5 \%$ dos participantes responderam que sim, essa medida pode vir a ser uma boa estratégia para melhorias na mobilidade urbana da cidade, $11 \%$ optaram por não saber responder a questão, contra 5,5\% não acreditam ser uma boa estratégia.

Em relação ao retorno dos atendimentos presenciais, pergunta-se aos participantes se continuariam optando pela atividade em Home Office e quais motivos, as respostas estão apresentadas no Gráfico 12. 
Gráfico 12. Caso houvesse a possibilidade, ainda com a retomada dos atendimentos presenciais, você optaria pelo Home Office? Por qual motivo?

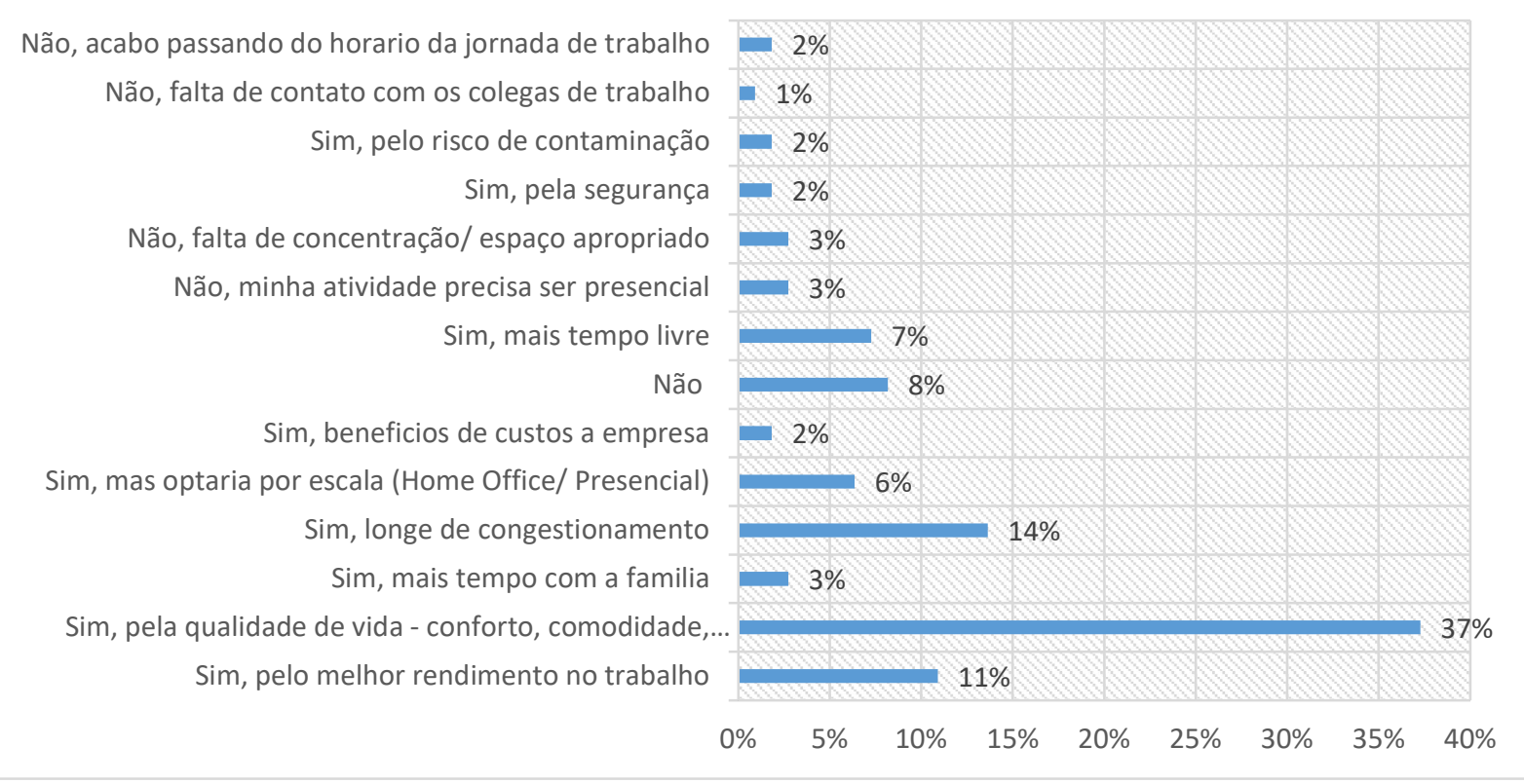

Fonte: Autores (2021)

Conforme apresentado, observa-se que o total de respostas positivas correspondem a $84 \%$ do total, sendo apresentado motivos relevantes como melhor qualidade de vida, não precisar enfrentar o congestionamento, transporte público e pelo melhor rendimento no trabalho. Em contra partida, o percentual total de $16 \%$ dos participantes, correspondem a não aderir ao Home Office pela falta de ambiente adequado, pela atividade exigir contato presencial e por acabar excedendo da jornada de trabalho.

O isolamento social, ocasionado pela pandemia, comprometeu a mobilidade urbana dos profissionais de São Paulo e submeteu empresas a trabalharem a distância, utilizando o Home Office como principal estratégia - $46 \%$ das empresas brasileiras optaram pela modalidade nesse período (MELLO, 2020). Esse crescimento consequentemente gerou impacto positivo na mobilidade urbana, pela redução desses profissionais no fluxo diário do transporte coletivo da cidade, sendo o ônibus o mais utilizado comparado aos demais, correspondendo a 43\% (MOBILIZE, 2018), contra 12\% do metrô e 3\% do trem, conforme pesquisa (REDE NOSSA SÃO PAULO E IBOPE INTELIGENCIA, 2018).

A pratica do Home Office se mostra atrativa para as organizações, é possível que ao fim da pandemia a mobilidade seja incorporada nas práticas de mercado em algumas atividades, gerando benefícios contínuos a mobilidade urbana de São Paulo, que recebe críticas de seus usuários diariamente sobre a super lotação, atrasos e baixa qualidade de serviço. 


\section{CONSIDERAÇÕES FINAIS}

De acordo com os resultados, mais do que a metade dos participantes utilizavam transporte público ao destino da empresa - integração metrô/trem e ônibus $(52,7 \%)$, somente metrô/trem $(19,8 \%)$ e somente ônibus (11\%) e em sua maioria levavam de 1 hora a 2 horas no trajeto. As maiores reclamações abordadas pelos participantes da pesquisa são: superlotação $(72,5 \%)$, estresse $(60,4 \%)$ e atrasos (58,2\%).

Observou-se na pesquisa, que $83,5 \%$ dos participantes acreditam que o Home Office pode vir a ser uma boa estratégia para minimizar os problemas de mobilidade urbana no Transporte Público, considerando ainda a permanência da pratica após o retorno presencial, com o fim da pandemia - $84 \%$ responderam que optariam pelo Home Office, principalmente por motivos relacionados a qualidade de vida, por não precisarem enfrentar congestionamentos e superlotações de transporte coletivo, utilizando esse tempo para descansar mais (36\%), realizar atividades de lazer (27\%) e estudar (22\%).

Diante dos dados apurados, concluiu-se que o isolamento social, medida de proteção adotada para a contenção da pandemia, resultou no crescimento do Home Office em 2020 e 2021, nesse contexto, consequentemente gerou impactou na mobilidade urbana da cidade.

O Home Office trouxe mudança comportamental de muitos profissionais e empresas, que aderiram a pratica no período de pandemia, reduziram a utilização do transporte e elevaram o tempo útil para produtividade dos profissionais, abrindo a reflexão para a possibilidade de diversos setores manterem suas atividades a distância após o fim do isolamento social.

Considera-se que este documento trata-se uma pesquisa de opinião, recomenda-se para futuras pesquisas um estudo similar em outras grandes cidades brasileiras e um estudo complementar desta pesquisa após o período de pandemia para verificar o impacto do Home Office ao ser decretado o fim da pandemia na cidade de São Paulo. 


\section{REFERÊNCIAS}

BRASIL. Lei Federal no 12.587/2012 Disponível em:

http://www.planalto.gov.br/ccivil_03/_ato2011-2014/2012/lei/l12587.htm. Acesso em: 14 mar. 2021

BRIDI, Maria Aparecida et al. 0 trabalho remoto/home-office no contexto da pandemia COVID19. Campinas, 2020. Disponível em:

https://www.eco.unicamp.br/remir/images/Artigos_2020/ARTIGO_REMIR.pdf. Acesso em: 19 mar. 2021.

GOVERNO DE SÃO PAULO. Entenda como funcionam os critérios e as fases da retomada da economia de São Paulo. São Paulo, 2020. Disponível em: https://www.saopaulo.sp.gov.br/wpcontent/uploads/2020/05/plano-sp-fases-e-criterios.pdf. Acesso em: 29 mar. 2021.

LOSEKANN, Raquel Gonçalves Caldeira Brant; MOURÃO, Helena Cardoso. Desafios do teletrabalho na pandemia covid-19: quando o home vira office. Caderno de Administração, v. 28, p. 71-75, 5 jun. 2020. Disponível em:

http://www.periodicos.uem.br/ojs/index.php/CadAdm/article/view/53637/751375150139.

Acesso em: 7 mar. 2021.

LIMA, Rossano Cabral. Distanciamento e isolamento sociais pela Covid-19 no Brasil: impactos na saúde mental. vol.30 no.2. ed. Rio de Janeiro: PHYSIS - Revista de Saúde Coletiva, 2020. Disponível em: https://www.scielo.br/scielo.php?script=sci_arttext\&pid=S0103-

73312020000200313\&tlng=pt. Acesso em: 14 mar. 2021.

MELLO, Daniel. Home office foi adotado por $\mathbf{4 6 \%}$ das empresas durante a pandemia. São Paulo:

Agência Brasil, 2020. Disponível em: https://agenciabrasil.ebc.com.br/economia/noticia/202007/home-office-foi-adotado-por-46-das-empresas-durante-pandemia. Acesso em: 7 mar. 2021.

REDE NOSSA SÃO PAULO E IBOPE INTELIGÊNCIA. Viver em São Paulo: mobilidade urbana na cidade. 2018. Disponível em: https://www.mobilize.org.br/midias/pesquisas/viver-em-sao-paulomobilidade-urbana-na-cidade.pdf. Acesso em: 14 mar. 2021

ORGANIZAÇÃO PAN-AMERICANA DE SAÚDE/ ORGANIZAÇÃO MUNDIAL DA SAÚDE. Folha Informativa Covid-19 - Escritório da OPAS e da OMS no Brasil. Disponível em:

https://www.paho.org/pt/covid19. Acesso em: 14 mar. 2021.

PREFEITURA DE SÃO PAULO. Disponível em: https://gestaourbana.prefeitura.sp.gov.br/marcoregulatorio/plano-

diretor/\#: :text=O\%20Plano\%20Diretor\%20Estrat\%C3\%A9gico\%20do,crescimento\%20da\%20cidad e\%20at\%C3\%A9\%202030. Acesso em: 14 mar. 2021

PREFEITURA DE SÃO PAULO. Plano diretor do município de São Paulo. Disponível em: https://gestaourbana.prefeitura.sp.gov.br/wp-content/uploads/2015/01/Plano-DiretorEstrat\%C3\%A9gico-Lei-n\%C2\%BA-16.050-de-31-de-julho-de-2014-Estrat\%C3\%A9giasilustradas.pdf. Acesso em: 14 mar. 2021 
SECRETARIA NACIONAL DE MOBILIDADE URBANA. Indicadores para monitoramento e avaliação da efetividade da Política Nacional de Mobilidade Urbana (PNMU).

SPTRANS. Disponível em:

https://www.sptrans.com.br/sptrans/\#: :text=S\%C3\%A3o\%20transportados\%2C\%20em\%20m\%C3 \%A9dia\%2C\%2010,voltas\%20ao\%20redor\%20da\%20terra. Acesso em: 14 mar. 2021

TAJRA, Alex. Https://noticias.uol.com.br/cotidiano/ultimas-noticias/2020/05/29/entenda-oscalculos-do-governo-e-como-sera-feita-a-reabertura-em-sao-paulo.htm. São Paulo: UOL, 2020. Disponível em: https://noticias.uol.com.br/cotidiano/ultimas-noticias/2020/05/29/entenda-oscalculos-do-governo-e-como-sera-feita-a-reabertura-em-sao-paulo.htm. Acesso em: 29 mar. 2021.

TCU- TRIBUNAL DE CONTAS DA UNIÃO. Áreas temáticas. Disponível em: https://portal.tcu.gov.br/tcu/paginas/contas_governo/contas_2010/fichas/Ficha\%205.2_cor.pdf. Acesso em: 14 mar. 2021

"Os autores declaram estar cientes quanto a responsabilidade pelo conteúdo do artigo." 